\title{
Development of Proton-Transfer \\ Ion Trap-Mass Spectrometry: \\ On-line Detection and Identification of Volatile Organic Compounds in Air
}

\author{
C. Warneke, ${ }^{*}$ J. A. de Gouw, ${ }^{*}$ E. R. Lovejoy, P. C. Murphy, \\ and W. C. Kuster \\ Aeronomy Laboratory, National Oceanic and Atmospheric Administration, Boulder, Colorado, USA \\ R. Fall* \\ Cooperative Institute for Research in Environmental Sciences, University of Colorado, Boulder, Colorado, USA
}

We present a newly developed instrument that uses proton-transfer ion trap-mass spectrometry (PIT-MS) for on-line trace gas analysis of volatile organic compounds (VOCs). The instrument is based on the principle of proton-transfer reaction-mass spectrometry (PTR-MS): VOCs are ionized using PTRs and detected with a mass spectrometer. As opposed to a quadrupole mass filter in a PTR-MS, the PIT-MS instrument uses an IT-MS, which has the following advantages: (1) the ability to acquire a full mass spectrum in the same time as one mass with a quadrupole and (2) extended analytical capabilities of identifying VOCs by performing collision-induced dissociation (CID) and ion molecule reactions in the IT. The instrument described has, at its current status, limits of detection between 0.05 and $0.5 \mathrm{pbbv}$ for 1-min measurements for all tested VOCs. The PIT-MS was tested in an ambient air measurement in the urban area of Boulder, Colorado, and intercompared with PTR-MS. For all measured compounds the degree of correlation between the two measurements was high $\left(r^{2}>0.85\right)$, except for acetonitrile $\left(\mathrm{CH}_{3} \mathrm{CN}\right)$, which was close to the limit of detection of the PIT-MS instrument. The two measurements agreed within less than $25 \%$, which was within the combined measurement uncertainties. Automated CID measurements on $\mathrm{m} / z 59$ during the intercomparison were used to determine the contributions of acetone and propanal to the measured signal; both are detected at $\mathrm{m} / \mathrm{z} 59$ and thus are indistinguishable in PTR-MS. It was determined that $m / z 59$ was mainly composed of acetone. An influence of propanal was detected only during a high pollution event. The advantages and future developments of PIT-MS are discussed. (J Am Soc Mass Spectrom 2005, 16, 1316-1324) (c) 2005 American Society for Mass Spectrometry

$\mathrm{V}$ olatile organic compounds (VOCs) in the atmosphere are emitted in large quantities from a variety of different natural and anthropogenic sources [1]. VOCs are key ingredients in the formation of ozone and aerosols and they play a significant role in determining regional air quality, in the chemistry of the global troposphere, and possibly the global carbon cycle [2]. Thus, there is continuing interest in the development of new methods for analysis of complex mixtures of VOCs in ambient air. Proton-transfer reaction-mass spectrometry (PTR-MS) is such a method and was developed by Lindinger and coworkers at the University of Innsbruck [3,4]. It is a method for on-line

Published online June 24, 2005

Address reprint requests to Dr. Carsten Warneke, NOAA Aeronomy Lab, 325 Broadway, Boulder, CO 80305. E-mail: carsten.warneke@noaa.gov

* Also with the Department of Chemistry and Biochemistry, University of Colorado, Boulder, $\mathrm{CO}$. measurements of trace amounts of VOCs in air, including many oxygenated VOCs. PTR-MS uses PTRs of hydronium ions $\left(\left[\mathrm{H}_{3} \mathrm{O}\right]^{+}\right)$to ionize VOCs in combination with mass spectrometric detection of the product ions. PTR-MS is well suited for studying the atmospheric chemistry of organic compounds, because it allows many important VOCs from natural and manmade origin to be measured along with their oxidation products. Three features that set PTR-MS apart from its alternatives such as gas chromatography mass spectrometry (GC-MS) for the analysis of VOCs in air are (1) the fast time response of only seconds or less, (2) the simultaneous analysis of numerous VOCs without a need for preconcentration or chromatographic separation, and (3) the capability of performing stand-alone measurements over extended periods of time. Lindinger et al. [4] have summarized the recent applications of PTR-MS.

In a PTR-MS measurement, only $\mathrm{m} / \mathrm{z}$ of the product 
ions can be determined, which is a valuable but certainly not unique indicator of the identity of trace gases. Clearly, different isomers of the same mass can not be resolved in this manner. The interpretation of the mass spectra is further complicated by the fragmentation of product ions and the formation of cluster ions, which may lead to additional mass overlap [5]. Recently, a method was developed that separates the contributions from different VOCs to a single mass channel by coupling a GC column to a PTR-MS instrument [6-8]. It was shown that a large number of VOCs could be unambiguously identified and quantified with this technique. The disadvantage of this method is that the acquisition of an air sample and the GC separation of the compounds take up to $30 \mathrm{~min}$, and the ability of performing fast on-line measurements is lost.

Here, we present an instrument similar to a PTR-MS instrument that uses an ion trap mass spectrometer (IT-MS) for the detection of ions. The extended analytical capabilities of the IT allow VOCs to be resolved that are normally indistinguishable in PTR-MS. The potential advantages of an IT over a quadrupole used in PTR-MS have recently been demonstrated by Prazeller et al. [9] and Warneke et al. [10]. The advantages are (1) an IT can analyze a range of masses of several 100 Th (Thompson) almost simultaneously whereas the quadrupole mass filter transmits only ions of one mass at a time. A mass spectrum of ions stored in the IT is generated in about $20 \mathrm{~ms}$, which is much shorter than the ion collection time; thus, the measurement efficiency per mass of the IT is significantly improved compared with the quadrupole. The increase in measurement efficiency is somewhat offset by the smaller collection efficiency of an IT relative to a quadrupole. (2) An IT has more analytical capabilities: collisioninduced dissociation (CID) and reactions can be performed in the IT. (3) In PTR-MS the ion chemistry is simplified by applying an electric field over the length of the drift tube reactor. This increases the ion kinetic energy, prevents ion clustering, and thus allows the interpretation of the product ion signals. Applying an electric field also limits the sensitivity, however. Because of the analytical capabilities of the IT, more cluster ions and, therefore, more complicated mass distributions, can be allowed in the drift reactor, which may allow the ion kinetic energy in the drift region to be decreased and the sensitivity to be increased.

In this study we present a newly developed instrument that combines a drift tube similar to the one used in PTR-MS with an IT-MS. The instrument design is described and performance tests are presented. Ambient atmospheric measurements of a number of different VOCs are used to demonstrate the instruments limits of detection and the feasibility of on-line VOC measurements at low mixing ratios. In addition, CID measurements for ambient trace gases are used to demonstrate the capability of the proton-transfer ion trap-mass spectometry (PIT-MS) instrument to distinguish between different VOCs of the same $m / z$.

\section{The PIT-MS Instrument}

\section{Instrument Setup}

The PIT-MS instrument shown in Figure 1 consists of four parts: (1) an all Teflon gas inlet and handling

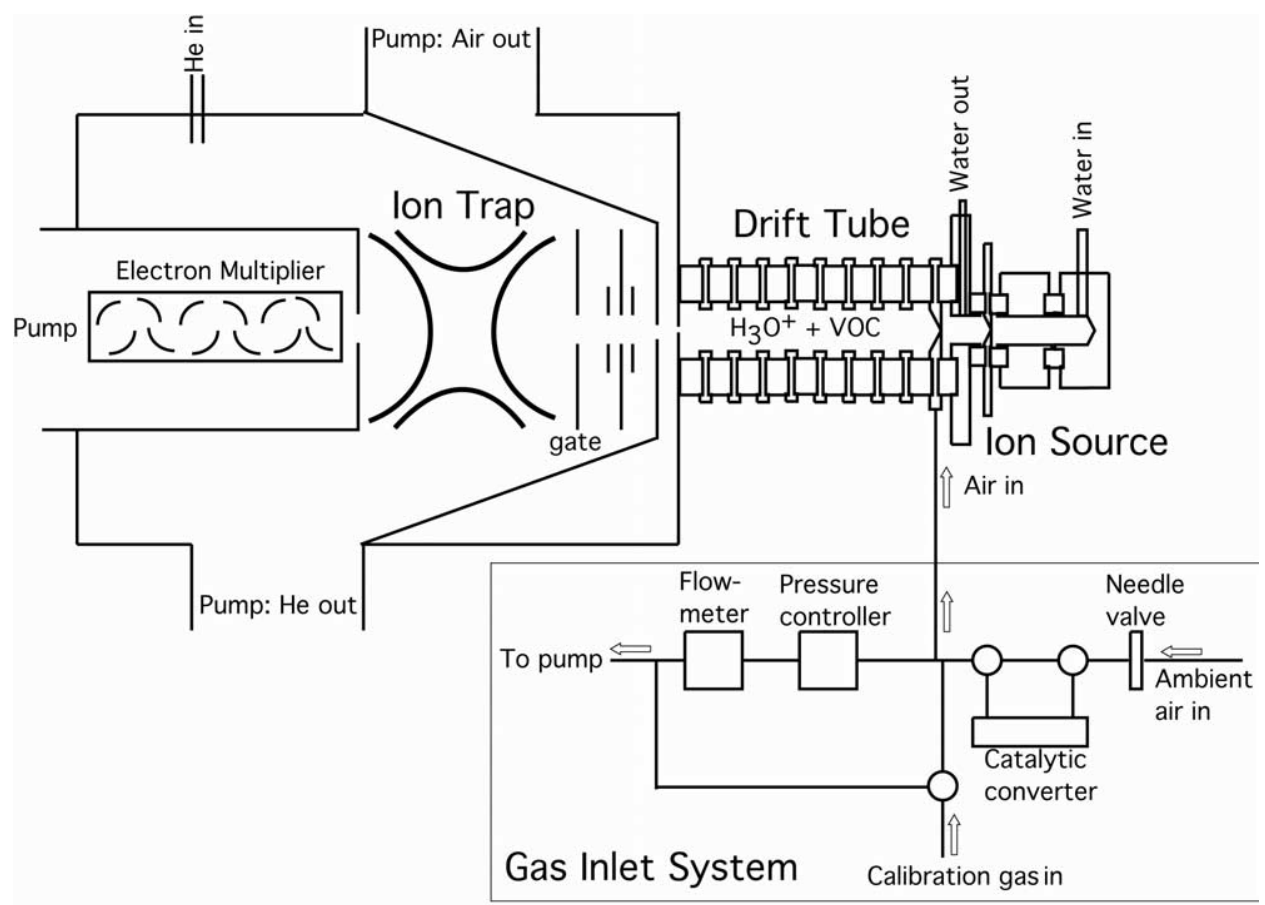

Figure 1. Schematic drawing of the PIT-MS instrument. 
system, (2) an ion source for the production of $\left[\mathrm{H}_{3} \mathrm{O}\right]^{+}$, (3) a drift tube reaction chamber, and (4) the detection system with the IT-MS and a secondary electron multiplier (SEM). The first three parts, similar to the PTR-MS instrument, were described in detail previously $[4,8$, 11] and will therefore be discussed only briefly here.

Gas inlet system. A diaphragm pump is used to pump the gas inlet system. A pressure controller regulates the flow through the inlet such that the inlet upstream of the controller is kept at a constant value. In this way the pressure in the drift tube of the PIT-MS instrument is kept constant and independent from the ambient pressure. About $30 \mathrm{STP} \mathrm{mL} \mathrm{min}^{-1}$ (STP = standard temperature of $273.15 \mathrm{~K}$ and pressure of $1.013 \mathrm{bar}$ ) sample air is diverted to the drift tube to maintain a pressure of 2.4 mbar. In this setup the sample air is only exposed to Teflon and Silcosteel (Reslek, Bellefonte, PA), which minimizes memory effects and the buildup of impurities in the inlet system. The system background levels, which have to be subtracted from the signal, are determined by passing the air through a catalytic converter using a three-way valve system. The converter effectively removes VOCs from the sample stream and keeps the humidity constant. Calibration gas can be added to the sample air downstream of the catalytic converter. Varying the inlet flow using a needle valve can produce a large range of calibration gas mixing ratios.

Ion source. Ions are produced in a hollow-cathode discharge in water vapor, which forms an intensive source of $\left[\mathrm{H}_{3} \mathrm{O}\right]^{+}$ions. A water vapor flow of about 4-8 STP $\mathrm{mL} \mathrm{min}^{-1}$ is pumped through the source of which about $5 \%$ reaches the drift tube, leading to an increased humidity of the sample air.

Drift tube reaction chamber. The ions are injected into the drift tube, which consists of $2 \mathrm{~cm}$ inner diameter (i.d.) stainless steel rings that are sealed and electrically isolated with Teflon rings and connected with resistors. A homogeneous electric field of up to $1000 \mathrm{~V}$ can be applied over the entire drift tube. The sample air (30 STP $\mathrm{mL} \mathrm{min}^{-1}$ ) is pumped through the drift tube and has a residence time of about $0.2 \mathrm{~s}$, which is one of the limiting factors for the response time of the instrument with memory effects being another one. Typical values in the drift tube used here were a $700 \mathrm{~V}$ electric field and 2.4 mbar pressure, which yields an $\mathrm{E} / \mathrm{N}$ value (electric field over gas number density) of about $118 \mathrm{Td}(1 \mathrm{Td}=$ $\left.10^{-17} \mathrm{~V} \mathrm{~cm}{ }^{2}\right)$. In the drift tube, PTRs between $\left[\mathrm{H}_{3} \mathrm{O}\right]^{+}$ and VOCs take place. Exiting the drift tube, the sample air is pumped away and a fraction of the ions $\left(\left[\mathrm{H}_{3} \mathrm{O}\right]^{+}\right.$ precursor ions and protonated VOCs) is extracted into the IT chamber. For a detailed description of the ionmolecule reactions in the drift tube, the determination of the sensitivity and a possible humidity dependence see de Gouw et al. [8] and Warneke et al. [11].
IT-MS. The IT used in the PIT-MS instrument has been described in detail by Lovejoy and Wilson [12], and recent modifications are discussed by Curtius et al. [13]. With a system of four lenses the ions are focused into the IT. The bias of the last lens can be controlled to gate ions into the trap. The IT has an internal radius of $1 \mathrm{~cm}$ and stretched endcap geometry. The IT pressure during all measurements was kept at $1 \times 10^{-3}$ mbar by adding ultrapure He to the IT chamber. About $5 \%$ of the gas in the IT chamber is sample air from the drift tube. Each endcap has a $1 \mathrm{~mm}$ diameter centered aperture. IT parameters of $r_{0}=1 \mathrm{~cm}$ and $f=1.01 \mathrm{MHz}$ give a relationship for the trapping parameter of $q_{z}=0.0479$ $\mathrm{V}_{\mathrm{p}-\mathrm{p}} / m$, where $\mathrm{V}_{\mathrm{p}-\mathrm{p}}$ is the peak-to-peak radio frequency (RF) voltage and $m$ is $m / z$ in Th [14]. Ions ejected through the exit endcap are accelerated onto a discrete dynode SEM, which is located in a differentially pumped chamber at a pressure of $1 \times 10^{-5}$ mbar.

The IT electronics consist of National Instruments PCI (Peripheral Component Interconnect) boards and a "LabView" program that control the ring electrode RF voltage, the lens gate bias, and endcap waveforms and also acquire data during the mass scan. Two different waveforms are applied to the IT endcaps: (1) filtered noise fields [15] (FNF) used for mass filtering during the ion-trapping period and also exciting trapped ions for CID and (2) sine waves used for axial modulation during the mass scan. The data acquisition electronics consist of a discrete dynode electron multiplier, a preamplifier, and an analog to digital converter. The software allows the user to adjust the timing and the amplitude of the RF voltage, the endcap waveforms, and the voltage that gates the ions into the IT and, therefore, give the ability to choose the trapping time, to perform fast mass scans of all trapped ions, to selectively trap specific ions, do CID on selected ions, and to perform ion-molecule reactions in the IT by adding reactant gases to the He buffer in the trap chamber.

Figure 2 shows a schematic of the voltages and fields that are typically applied to the IT to acquire a mass scan. At the beginning of each cycle the IT is emptied of all ions by closing the ion gate and switching off the RF amplitude on the ring electrode. The gate is applied to the last lens in front of the IT. During the trapping time the lens is used to focus the ions into the trap (ions on); during the rest of the time the lens is used to block the ions from entering (ions off). To trap ions, the gate is opened and a low amplitude RF field, typically 500-700 $\mathrm{V}$ peak-to-peak, is applied to the ring electrode. The trapping time can be varied from $1 \mathrm{~ms}$ up to several seconds and is chosen depending on the expected ion signals. This means that the trap can be filled until the desired number of ions is stored, although no automatic gain control is used here. On the other hand, too large a number of ions, confined in the small volume of the IT, will cause space charge effects and a distortion of the mass scans.

During the trapping an FNF can be applied to the endcaps for selectively trapping or removing specific 


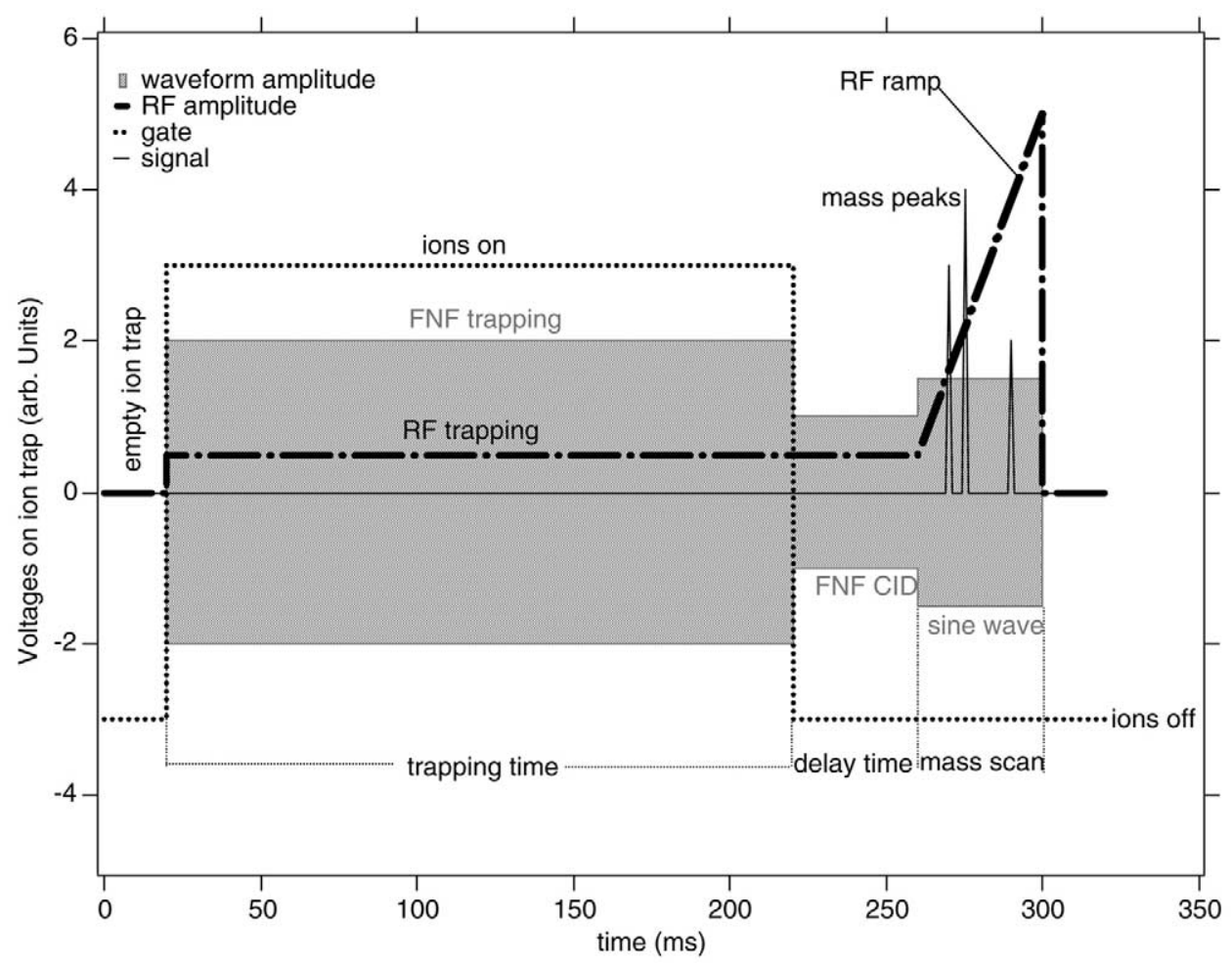

Figure 2. A typical IT control sequence.

ions. After the trapping time the gate is closed and the ions can be stored for a variable length of time. During this delay time a second FNF can be applied for CID of trapped ions or reactions in the trap can be performed. Hereafter, the RF amplitude is ramped up, which increases the amplitude of the trajectories of the trapped ions and they are ejected from the IT starting with low $\mathrm{m} / \mathrm{z}$ and increasing with RF amplitude. This is called the mass selective instability mode [16]. The ions exiting the IT are detected with the SEM and the ion current is measured. All parameters controlling the trap are variable providing full control over the analytical capabilities of the IT.

The PIT-MS instrument is built into a standard double column 19 in. rack with a height of $60 \mathrm{~cm}$. It weighs about $130 \mathrm{~kg}$ and has a total power consumption of about $1.2 \mathrm{~kW}$.

\section{Measurement Procedure}

In the IT, only about $2 \times 10^{4}-1 \times 10^{5}$ ions can be stored before space charge effects distort the mass scans. To estimate the number of ions that are overfilling the IT, the measured gain of the SEM was used together with an estimated efficiency of the extraction of the ions from the IT. The IT is filled with primary ions in about $50-100 \mathrm{~ms}$, which is too short to detect small mixing ratios of product ions. To measure small mixing ratios in air, trapping times of product ions of at least $1 \mathrm{~s}$ are necessary and therefore primary and product ions can not be measured at the same time. In Figure 3 two mass scans are shown, one from primary and one from product ions. The primary ions in Figure 3a were measured with a trapping time of $50 \mathrm{~ms}$ and an RF amplitude was chosen that allows for trapping $\mathrm{m} / \mathrm{z}$ as low as 12 Th. No auxiliary FNF field was applied to the endcaps. It should be mentioned that the trapping efficiency of $\mathrm{m} / \mathrm{z} 19\left(\left[\mathrm{H}_{3} \mathrm{O}\right]^{+}\right)$is about a factor of $4-8$ lower than all other $\mathrm{m} / \mathrm{z}$ values. The trapping efficiency was measured by adding such high mixing ratios of VOCs to the drift tube that $\left[\mathrm{H}_{3} \mathrm{O}\right]^{+}$was completely reacted away. The ratio of precursor to product ion signals yields a trapping efficiency difference. The impurity $\mathrm{O}_{2}^{+}$ions in the primary ions signal therefore are only $3-5 \%$, even though the percentage seems higher in Figure $3 a$.

The product ion mass scan in Figure $3 b$ was produced by diluting a calibrated VOC gas standard consisting of methanol, acetonitrile, acetaldehyde, acetone, dimethyl sulfide, benzene, and toluene to about 50 ppbv. The trapping time is $2 \mathrm{~s}$ and an RF amplitude was chosen that allows for the trapping of $\mathrm{m} / \mathrm{z}$ starting at 20 Th, which eliminates $\left[\mathrm{H}_{3} \mathrm{O}\right]^{+}$from the mass scan. During the trapping an FNF field is applied to the endcaps to eliminate $\mathrm{m} / \mathrm{z} 30,32$, and $37 \mathrm{Th}$, which allows for long trapping times of the product ions without overfilling the IT with primary ions.

The increase in ion signal with the length of the trapping time is shown in Figure 4a. Using the same calibration standard the product ions were trapped with varying trapping times. The detected ion signals increase linearly with the trapping time until the IT is 


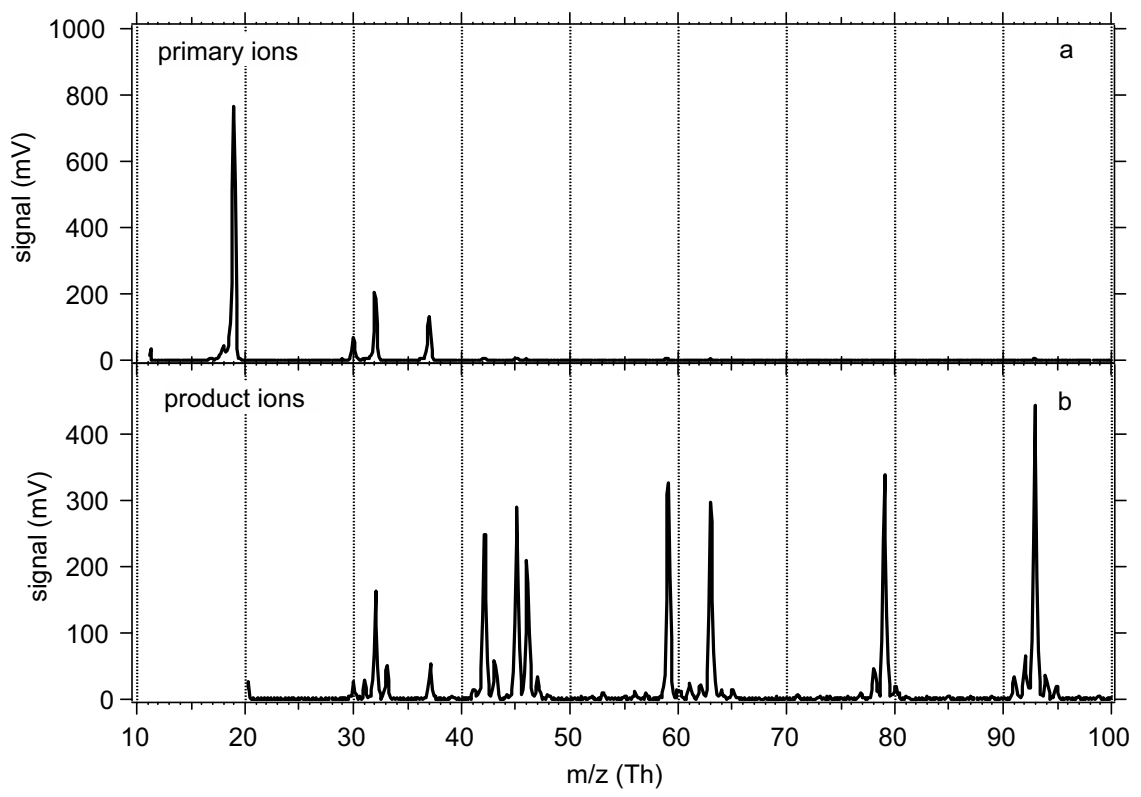

Figure 3. (a) A mass scan of the primary ions of $\left[\mathrm{H}_{3} \mathrm{O}\right]^{+}(19 \mathrm{Th}),\left[\mathrm{H}_{3} \mathrm{O} . \mathrm{H}_{2} \mathrm{O}\right]^{+}(37 \mathrm{Th}),\left[\mathrm{O}_{2}\right]^{+}(32 \mathrm{Th})$, and $\left[\mathrm{NO}^{+}(30 \mathrm{Th})\right.$; starting at $\mathrm{m} / \mathrm{z} 12$, the trapping time is $50 \mathrm{~ms}$ and no FNF is applied. (b) A mass scan of product ions of a calibration gas containing about $50 \mathrm{ppbv}$ of methanol (33 Th), acetonitrile (42 $\mathrm{Th})$, acetaldehyde $(45 \mathrm{Th})$, acetone ( $59 \mathrm{Th})$, dimethyl sulfide $(63 \mathrm{Th})$, benzene $(79 \mathrm{Th})$, and toluene (93 Th). The mass scan starts at $m / z 20$, the trapping time is $2 \mathrm{~s}$, and an FNF field is applied to eliminate $\mathrm{m} / \mathrm{z} 30,32$, and 37 .

overfilled. Increasing the trapping time therefore increases the sensitivity (in $\mathrm{mV} \mathrm{ppbv}^{-1}$ ) of the PIT-MS instrument, but results in a decreased time resolution.

Figure $4 \mathrm{~b}$ shows that ions can be stored in the IT for several seconds with only minor losses. The same calibration mixture was used to produce ions, which were collected for $1 \mathrm{~s}$ and then stored in the trap with a variable delay time. After $10 \mathrm{~s}$ of storing about $40 \%$ of the ions are lost from the IT.

\section{Humidity Dependence and Calibrations}

A discussion of the humidity dependence and the calibration procedure of VOCs measured with this drift tube reactor, similar to that used in PTR-MS instruments, can be found elsewhere $[7,8,11,17]$ and will be only briefly summarized here.

Because of variations in the intensity of the ion source and the humidity of the sample air, the signals of $\left[\mathrm{H}_{3} \mathrm{O}\right]^{+}$and $\left[\mathrm{H}_{3} \mathrm{O}\right]^{+}\left(\mathrm{H}_{2} \mathrm{O}\right)$ are not constant. To account for the varying primary ion signals, the product ion signals are normalized to a standard primary ion signal of $1000 \mathrm{mV} \mathrm{u}$ (the integrated ion signal; the ion current during a mass scan is measured with a current to voltage amplifier and the area under the peak is calculated by integrating the mass peak) using the following equation $[7,8,11,17]$ :

$$
\begin{gathered}
\text { normalized ion signal } \\
=1000 \times \frac{i\left([R H]^{+}\right)}{i\left(\left[\mathrm{H}_{3} \mathrm{O}\right]^{+}\right)+\mathrm{X}_{R} \times i\left(\left[\mathrm{H}_{3} \mathrm{O}\right]^{+}\left(\mathrm{H}_{2} \mathrm{O}\right)\right)}
\end{gathered}
$$

where $i\left(\left[\mathrm{H}_{3} \mathrm{O}\right]^{+}\right)$and $i\left(\left[\mathrm{H}_{3} \mathrm{O}\right]^{+}\left(\mathrm{H}_{2} \mathrm{O}\right)\right)$ are the ion signals of $\left[\mathrm{H}_{3} \mathrm{O}\right]^{+}$and $\left[\mathrm{H}_{3} \mathrm{O}\right]^{+}\left(\mathrm{H}_{2} \mathrm{O}\right)$ measured with a $50 \mathrm{~ms}$ trapping time and $i\left(R H^{+}\right)$is the product ions measured at a $1000 \mathrm{~ms}$ trapping time. The normalized ion signal is given in units of $\mathrm{nmV} u$ (normalized milliVolt mass unit) (normalized integrated ion signal). The factors $X_{R}$ are compound specific and reflect both the mass-dependent detection efficiency for $\left[\mathrm{H}_{3} \mathrm{O}\right]^{+},\left[\mathrm{H}_{3} \mathrm{O}\right]^{+}\left(\mathrm{H}_{2} \mathrm{O}\right)$, and $R$, and the difference in rate coefficient for the $\left[\mathrm{H}_{3} \mathrm{O}\right]^{+}+$ $R$ and $\left[\mathrm{H}_{3} \mathrm{O}\right]^{+}\left(\mathrm{H}_{2} \mathrm{O}\right)+R$ proton transfer reactions. Values for $X_{R}$ are determined by measuring constant mixing ratios of each $\mathrm{VOC}$ at varying humidity, which changes the ratio of $\left[\mathrm{H}_{3} \mathrm{O}\right]^{+}$and $\left[\mathrm{H}_{3} \mathrm{O}\right]^{+}\left(\mathrm{H}_{2} \mathrm{O}\right)[7,8,11$, 17].

In principle, the response of the PIT-MS instrument with respect to specific VOCs can be calculated from the instrumental conditions and the rate coefficient for the PTR with $\left[\mathrm{H}_{3} \mathrm{O}\right]^{+}[4,7]$. Because the uncertainties in the rate coefficient can be substantial $(50 \%)$ and to a lesser extent to account for possible inlet losses, calibration measurements are performed to achieve better accuracy. A typical calibration curve is shown in Figure 5. A small flow ( 3 STP $\mathrm{mL} \mathrm{min}^{-1}$ ) of the standard mix is diluted in varying flows of ambient air, which is cleaned from VOCs with the catalytic converter (see Figure 1, gas inlet system). By changing the PIT-MS instrument's inlet flow using the Teflon needle valve, mixing ratios of $1-70 \mathrm{ppbv}$ can be generated. The response of the PIT-MS instrument over this mixing ratio range is linear for all measured VOCs (Figure 5). The slope of each curve yields the sensitivity (or cali- 
bration factor) for each species in $\mathrm{nmV} u \mathrm{ppbv}^{-1}$. For some species an offset in the response is measured because of impurities in the system or the presence of unwanted ions from the ion source. During measurements this offset is determined by passing the air frequently through the catalytic converter and is subtracted from the signal. Using these calibration measurements, the mixing ratios in the ambient air measurements, described in the next section, was determined.

\section{Ambient Air Measurements}

\section{Limit of Detection}

To verify the ability of the PIT-MS instrument to measure on-line sub-ppbv (parts per billion volume) mixing ratios, ambient air measurements using a PIT-MS and a PTR-MS instrument were conducted in the urban area of Boulder, Colorado. Figure 6 shows the six different VOC mixing ratios measured via both PIT-MS and
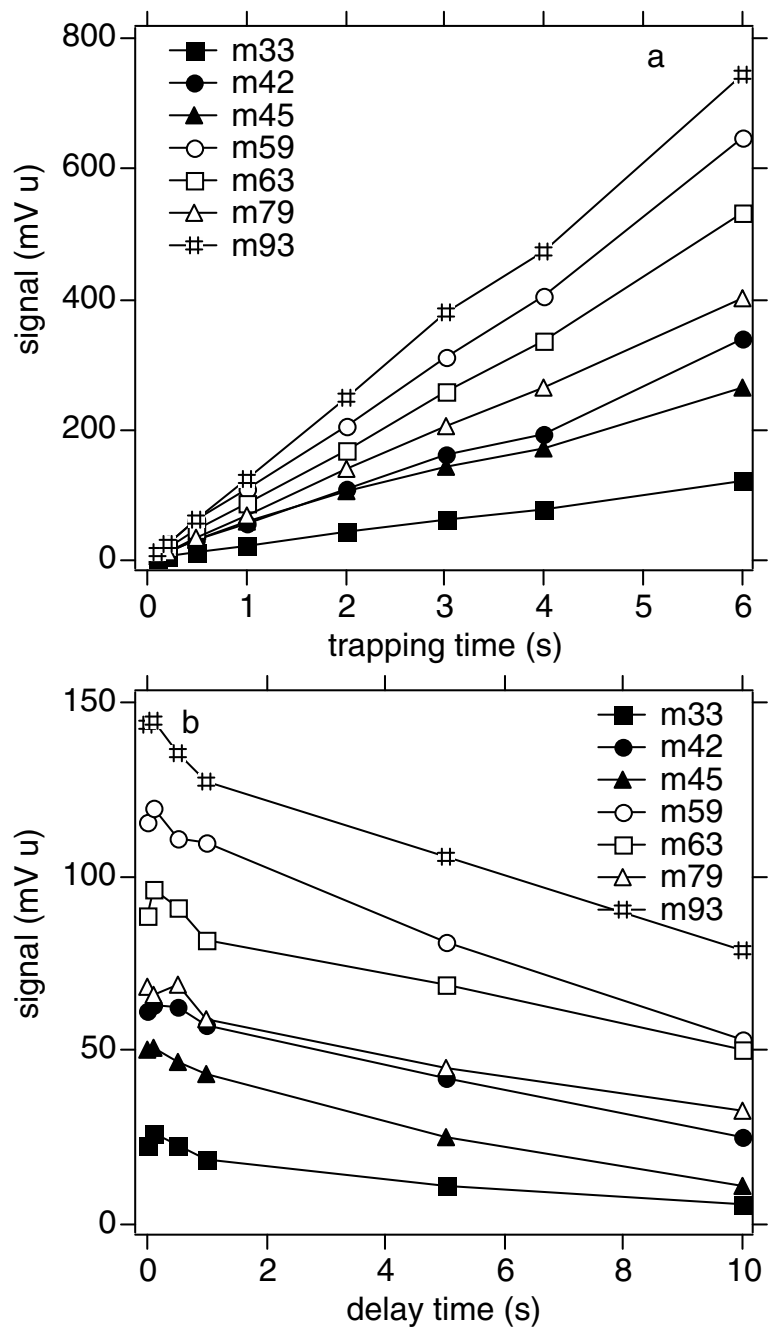

Figure 4. (a) The increase in signal with trapping time. (b) Decrease in signal with the time the ions are stored in the IT after trapping.

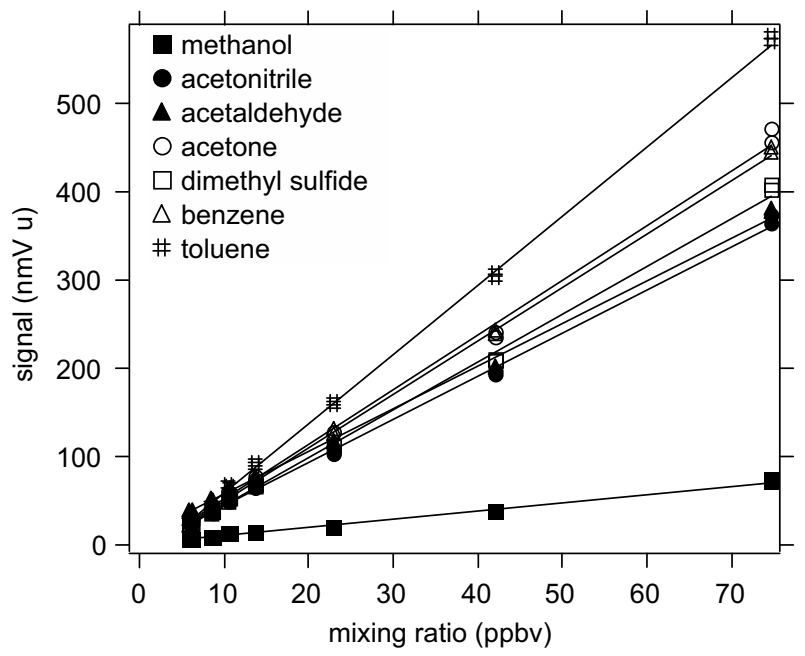

Figure 5. Result of a typical calibration measurement of the PIT-MS.

PTR-MS instruments as a function of time. The PIT-MS measurements were all done in the regular mass scan mode. The mixing ratios were determined as described earlier by normalizing to the primary ion signal, subtracting the instrument background measured with the catalytic converter, and dividing by the calibration factor. The trapping time used for the product ions was

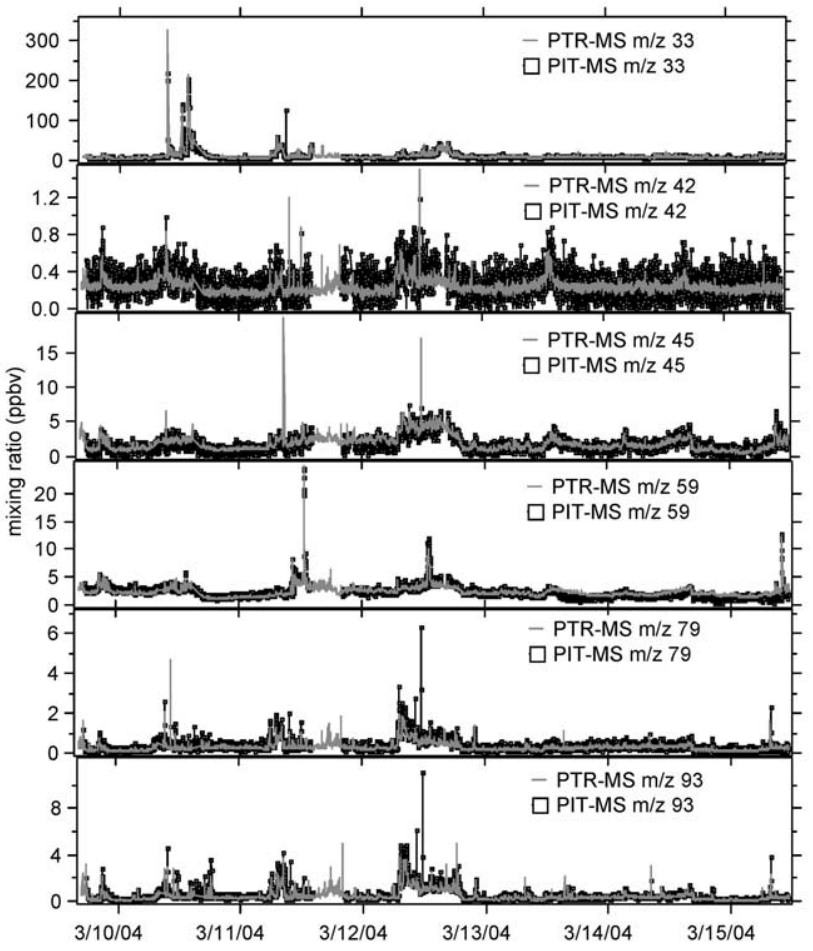

Figure 6. Time series of 1-min measurements of the mixing ratios of methanol, acetonitrile, acetaldehyde, acetone, benzene, and toluene measured simultaneously with PIT-MS and PTR-MS in Boulder, Colorado. 
Table 1. PIT-MS data on six VOCs including the quantification ions, sensitivity and limits of detection (LOD) for a 1-min trapping time ( $/ \mathrm{N}=3)$, and corresponding limits of detection for PTR-MS, and the slope and $r^{2}$ of the intercomparison

\begin{tabular}{lcccccc}
\hline Compound & $\begin{array}{c}\mathrm{m} / z \\
{[\mathrm{Th}]}\end{array}$ & $\begin{array}{c}\text { PIT-MS } \\
\text { LOD } \\
{[\mathrm{pptv}]}\end{array}$ & $\begin{array}{c}\text { PTR-MS } \\
\text { LOD } \\
{[\mathrm{pptv}]^{\mathrm{a}}}\end{array}$ & $\begin{array}{c}\text { Sensitivity } \\
{[\mathrm{nmV} \mathrm{u}} \\
\left.\mathrm{ppbv}^{-1}\right]\end{array}$ & $\begin{array}{c}\text { Slope } \\
\text { intercomparison }\end{array}$ & $\begin{array}{c}\mathrm{r}^{2} \\
\text { Intercomparison }\end{array}$ \\
\hline \hline Methanol & 33 & 500 & 250 & 2.4 & 0.98 & 0.99 \\
Acetonitrile & 42 & 110 & 34 & 4.2 & 1.12 & 0.60 \\
Acetaldehyde & 45 & 450 & 220 & 4.1 & 0.93 & 0.85 \\
Acetone & 59 & 240 & 84 & 5.3 & 1.20 & 0.90 \\
Benzene & 79 & 90 & 46 & 5.2 & 1.24 & 0.87 \\
Toluene & 93 & 50 & 33 & 6.71 & 1.21 & 0.93 \\
\hline
\end{tabular}

Key: LOD, limits of detection; PIT-MS, proton-transfer ion trap-maspectrometry; PTR-MS, proton-transfer reaction-mass spectrometry; S/N, signal to noise; VOCs, volatile organic compounds.

aTaken from Ref. [17]: measurement frequency: $5 \mathrm{~s}$ per $\mathrm{m} / \mathrm{z}$ every $2.25 \mathrm{~min}$.

$5 \mathrm{~s}$ and 12 mass spectra were averaged to yield 1-min measurements.

Limits of detection are estimated as three times the standard deviation in the background measurements [11] and are given in Table 1 for 1-min integration periods. For comparison, the limits of detection for PTR-MS determined during the NEAQS2002 (New England Air Quality Study 2002) campaign are also given in Table 1. The lower limits of detection are a result of the higher sensitivity of the PTR-MS than the PIT-MS instrument, but the sensitivity of the latter is subject to continued improvement.

\section{Intercomparison with PTR-MS}

Figure 6 also shows the results of PTR-MS measurements along with the PIT-MS data. The data presented for both instruments are 1-min measurements. It can be seen that the two instruments agree well, although the PIT-MS instrument has more noise on the signal mainly because of the lower sensitivity compared with the PTR-MS. The correlation coefficients and the slopes of the intercomparison for all six compounds are given in Table 1. For all six VOCs $r^{2}$ is higher than 0.85 , except for acetonitrile, where the mixing ratios were close to the limits of detection of the PIT-MS. The percent difference between PIT-MS and PTR-MS measurements was less than $25 \%$ for all compounds. Because different calibration procedures (different setup and flow controllers) were used for both instruments, we consider these differences to be within the expected uncertainties. Furthermore, the humidity dependence of the PIT-MS has to be investigated in more detail, but a full characterization and validation of the sensitivity and humidity dependence of the newly developed PIT-MS instrument are beyond the scope of this work.

\section{CID}

As described earlier, the IT has extended analytical capabilities compared with the quadrupole mass spectrometer used in conventional PTR-MS [9, 10]. Using the PIT-MS instrument CID was performed every 45 $\min$ on $\mathrm{m} / \mathrm{z} 59$ during the intercomparison experiment.
Ions at $\mathrm{m} / \mathrm{z} 59$ were isolated in the IT and were subsequently excited and fragmented using an FNF at increasing amplitudes. Figure $7 \mathrm{a}$ repeats the measured time series of $m / z 59$ from Figure 6, and Figure 7c shows one typical CID measurement of $\mathrm{m} / \mathrm{z} 59$ that was taken during an episode of high $\mathrm{m} / \mathrm{z} 59$ mixing ratios. The relative abundance of the precursor ion and the product ions $m / z 31$ and $m / z 41$ are plotted, where on the top axis the time of the measurement and on the bottom axis the respective amplitude of the CID FNF field is shown. One CID measurement in the mode used here takes about $4 \mathrm{~min}$. To reduce the time for CID, fewer or only one sufficiently high amplitude could be chosen to determine the fragment ions. In the urban atmosphere, both acetone and propanal are expected to contribute to the signal measured on $\mathrm{m} / \mathrm{z} 59$, where higher mixing ratios of acetone are usually encountered because of its higher emissions and longer atmospheric lifetime [17].

In Figure 7d, e, CIDs of pure acetone and propanal are shown. Fragmentation patterns for acetone and propanal in an IT-MS were proposed by Prazeller et al. [9]. For acetone, $m / z 41$ is $\mathrm{CH}_{2}=\mathrm{CCH}_{3}^{+}$and $m / z 31$ is $\mathrm{CH}_{3} \mathrm{O}^{+}$, and for propanal, $m / z$ is $\mathrm{CH}_{3} \mathrm{CH}=\mathrm{CH}^{+}$and $\mathrm{m} / \mathrm{z} 31$ is $\mathrm{CH}_{3} \mathrm{O}^{+}$. The intensity ratio of $(\mathrm{m} / \mathrm{z} 31) /(\mathrm{m} / \mathrm{z} 41)$ at higher FNF CID amplitudes is different for the two compounds ( 0.6 for propanal and 2.0 for acetone), which could be used to distinguish between the two compounds $[9,10]$. The fragmentation of $m / z 59$ in the ambient air measurements looks similar to that for acetone with a maximum $(\mathrm{m} / \mathrm{z}$ $31) /(m / z 41)$ intensity ratio of about 2 . The intensity ratio of $(m / z 31) /(m / z 41)$, averaged over the FNF amplitudes $0.12,0.14$, and $0.16 \mathrm{~V}$ is plotted versus time in Figure $7 \mathrm{~b}$. One point in Figure $7 \mathrm{~b}$ represents one CID measurement as presented in Figure 7c. For almost the entire measurement period the measured $(\mathrm{m} / \mathrm{z} 31) /(\mathrm{m} / \mathrm{z} 41)$ intensity ratio is very close to that of acetone. This shows that the signal measured on $\mathrm{m} / \mathrm{z} 59$ can be attributed mainly to acetone with a small contribution of propanal during a short period of time around 12:00 p.m. on April 10, 2004. During this time period very high mixing ratios of methanol and other VOCs were measured, which indicates fresh pollution or a change to emission sources that contain relatively more propanal. The error bars on the $(\mathrm{m} / \mathrm{z} 31) /(\mathrm{m} / \mathrm{z} 41)$ intensity ratio are the inverse of the $\mathrm{m} / z 59$ mixing ratio to 


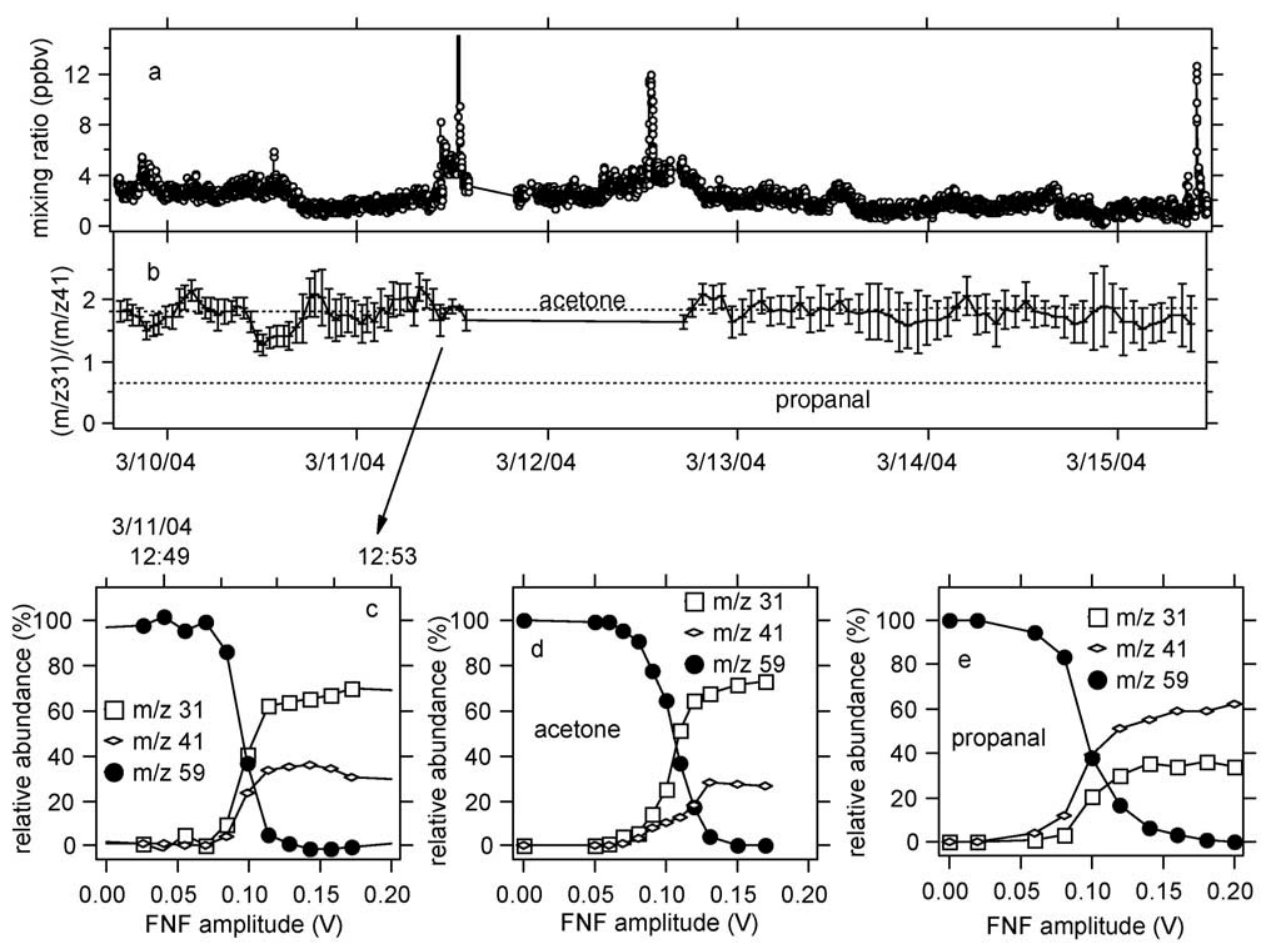

Figure 7. (a) A time series of acetone mixing ratio. (same as Figure 6) (b) Intensity ratio of $(\mathrm{m} / \mathrm{z}$ 31) $/(\mathrm{m} / \mathrm{z} 41)$ at an FNF amplitude of $0.14 \mathrm{~V}$ vs. time. The dotted lines show the ratios for pure acetone and propanal. (c) One single CID measurement of $m / z 59$ of ambient air. (d) CID measurement of pure acetone. (e) CID measurement of pure propanal.

show where low signals can cause higher uncertainties in the ratio. CID measurements on $\mathrm{m} / \mathrm{z} 59$ can be used to measure the contribution of acetone and propanal at mixing ratios as low as $0.5 \mathrm{ppbv}$.

CID measurements, as presented here for $m / z 59$, can be performed automatically on a large number of $\mathrm{m} / \mathrm{z}$ and clearly increase the specificity of PIT-MS compared with PTR-MS.

\section{Conclusion}

Here, we presented a newly developed instrument (PIT-MS) for on-line trace gas analysis that uses PTR with $\left[\mathrm{H}_{3} \mathrm{O}\right]^{+}$to ionize VOCs, similar to PTR-MS, and an IT-MS for the detection. The instrument described has at the current status a limit of detection below $0.5 \mathrm{ppbv}$ for 1-min measurements of all investigated VOCs. During an ambient air measurement the PIT-MS was compared with a conventional PTR-MS instrument and showed good agreement. The analytical capabilities of the IT were demonstrated by doing CID on $\mathrm{m} / \mathrm{z} 59$, confirming that mostly acetone contributes to the signal on $\mathrm{m} / \mathrm{z} 59$. Only during high pollution events was an influence of propanal detected.

The PIT-MS instrument has clear advantages over conventional PTR-MS: as opposed to a PTR-MS measurement no ions have to be selected for monitoring before a PIT-MS measurement. Furthermore, the PIT-MS instrument has extended analytical capabilities for identifying VOCs by performing CID and ion- molecule reactions in the IT. These analytical capabilities could be used to improve the sensitivity. At the present stage the sensitivity of the PIT-MS instrument is still lower than of the PTR-MS (about a factor of five, dependent on the measurement setup) and needs to be improved. Current developments to increase the sensitivity include the use of an octopole ion guide, replacing the lens system to transport the ions from the drift tube and to focus them into the IT. Furthermore, the orifice size in the endcaps could be increased, which would allow more ions to enter the trap but would reduce the mass resolution somewhat.

\section{Acknowledgments}

The authors acknowledge useful discussions with Peter Prazeller and Michael Alexander of the Pacific Northwest National Laboratory and are grateful to Frans Harren of the University of Nijmegen in the Netherlands and Shuji Kato of the University of Colorado in Boulder for their input during their respective visits to our laboratory. This work was funded by the National Science Foundation (project ATM-0207587). During the early stages of this project, financial support was obtained from the Dutch Foundation for Fundamental Research of Matter (FOM) and useful design studies were performed by Stefan Luxembourg presently with AMOLF in Amsterdam, the Netherlands.

\section{References}

1. Hewitt, C. N. Reactive Hydrocarbons in the Atmosphere; Academic Press: San Diego, 1999. 
2. Crutzen, P. J. Role of $\mathrm{NO}$ and $\mathrm{NO}_{2}$ in the Chemistry of the Troposphere and Stratosphere. Annu. Rev. Earth Planet. Sci. 1979, 7, 443.-472.

3. Lindinger, W.; Fall, R.; Karl, T. Environmental, Food and Medical Applications of Proton-Transfer-Reaction Mass Spectrometry (PTR-MS). Adv. Gas Phase Ion Chem. 2001, 4, 1-48.

4. Lindinger, W.; Hansel, A.; Jordan, A. Online Monitoring of Volatile Organic Compounds at pptv Levels by Means of Proton-Transfer-Reaction Mass Spectrometry (PTR-MS): Medical Applications, Food Control and Environmental Research. Int. J. Mass. Spectrom. Ion Process. 1998, 173, 191-241.

5. Williams, J.; Pöschl, U.; P. J., C.; Hansel, A.; Holzinger, R.; Warneke, C.; Lindinger, W. An Atmospheric Chemistry Interpretation of Mass Scans Obtained from a Proton Transfer Mass Spectrometer Flown Over the Tropical Rainforest of Surinam. J. Atmos. Chem. 2001, 38, 133-166.

6. Karl, T.; Fall, R.; P. J., C.; Jordan, A.; Lindinger, W. High Concentrations of Reactive Biogenic VOCs at a High Altitude Site in Late Autumn. Geophys. Res. Lett. 2001, 28, 507-510.

7. Warneke, C.; de Gouw, J. A.; Goldan, P. D.; Kuster, W. C.; Fall, R. Validation of Atmospheric Measurements by Proton-Transfer-Reaction Mass Spectrometry Using a Gas-chromatographic Pre-separation Method. Environ. Sci. Tech. 2003, 37, 2494-2501.

8. de Gouw, J. A.; Warneke, C.; Karl, T.; Eerdekens, G.; van der Veen, C.; Fall, R. Sensitivity and Specificity of Atmospheric Trace Gas Detection by Proton-Transfer-Reaction Mass Spectrometry. Int. J. Mass Spectrom. 2003, 365-382.

9. Prazeller, P.; Palmer, P. T.; Boscaini, E.; Jobson, T.; Alexander, M. Proton Transfer Reaction Ion Trap Mass Spectrometry. Rapid Commun. Mass Spectrom. 2003, 17, 1593-1599.

10. Warneke, C.; Rosen, S.; Lovejoy, E. R.; de Gouw, J. A.; Fall, R. Two Additional Advantages of Proton Transfer Ion Trap Mass
Spectrometer (PT-ITMS). Rapid Commun. Mass Spectrom. 2004 $18,133-134$.

11. Warneke, C.; van der Veen, C.; Luxembourg, S. L.; de Gouw, J. A.; Kok, A. Measurements of Benzene and Toluene in Ambient Air Using Proton-transfer-reaction Mass Spectrometry: Calibration, Humidity Dependence and Field Intercomparison. Int. J. Mass Spectrom. 2001, 207, 167-182.

12. Lovejoy, E. R.; Wilson, R. R. Kinetic Studies of Negative Ion Reactions in a Quadrupole Ion Trap: Absolute Rate Coefficients and Ion Energies. J. Phys. Chem. A 1998, 102, 2309-2315.

13. Curtius, J.; Froyd, K. D.; Lovejoy, E. R. Cluster Ion Thermal Decomposition (I): Experimental Kinetics Study and $\mathrm{Ab}$ Initio Calculations for $\mathrm{HSO}_{4}^{-}\left(\mathrm{H}_{2} \mathrm{SO}_{4}\right)_{\mathrm{x}}\left(\mathrm{HNO}_{3}\right)_{\mathrm{y}}$. J. Phys. Chem. A 2001, 105, 10867-10873.

14. March, R. E.; Hughes, R. J. Practical Aspects of Ion Trap Mass Spectrometry, Vol. I-III; Wiley: New York; CRC: Boca Raton, FL, 1995.

15. Cheng, L.; Wang, T. C. L.; Ricca, T. C.; Marshall, A. G. Phase-modulated Stored Waveform Inverse Fourier Transform Excitation for Trapped Ion Mass Spectrometry. Anal. Chem. 1987, 449-454.

16. Stafford, G.; Kelley, P.; Syka, J.; Reynolds, W.; Todd, J. Recent Improvements In and Analytical Applications of Advanced Ion Trap Technology. Int. J. Mass Spectrom. Ion Process. 1984, 60.

17. de Gouw, J. A.; Goldan, P. D.; Warneke, C.; Kuster, W. C.; Roberts, J. M.; Marchewka, M.; Bertman, S. B.; Pszenny, A. A. P.; Keene, W. C. Validation of Proton-Transfer-Reaction Mass Spectrometry (PTR-MS) Measurements of Gas-Phase Organic Compounds in the Atmosphere During the New England Air Quality Study (NEAQS) in 2002. J. Geophys. Res. 2003, 108, 10.1029/2003JD003863. 